\title{
Evaluation of Traditional Medicines III: The Mechanism of Immune Modulation by PHELA.
}

\section{Makhotso Lekhooa*, Andrew Walubo*, Jan JB Du Plessis*, and Motlalepula G. Matsabisa"1}

\author{
*University of the Free State, Department of Pharmacology \\ ${ }^{1}$ Medical Research Council, Indigenous Knowledge Systems (Health) Unit \\ P.O.Box 19070, Tygerberg 7505, Francie van Zijl Drive Parow Valley, Cape Town, South Africa
}

\#E-mail: motlalepula.matsabisa@mrc.ac.za

\begin{abstract}
PHELA is a herbal traditional medicine that is under development for use as an immune booster in immune compromised individuals. Therefore, the aim of this study was to determine PHELA's mechanism of action by observing for changes in cytokine profiles. Four groups of Sprague Dawley rats $(n=8)$ were treated daily and separately with normal-saline, cyclosporine-A, PHELA-only and PHELA+ cyclosporine-A. Thereafter, 4 animals from each group were sacrificed after 7 and 14 days of treatment. Serum Th1 cytokines (IL-2, IFN-y and TNF-á) and Th2 cytokines (IL-4 and IL-10) were measured by ELISA. The concentrations of Th1 cytokines in the PHELA-only treated group were similar to the control group on days 7 and 14. However, the Th1 cytokines were higher in the PHELA+cyclosporine-A treated group compared to cyclosporine-A group, and cyclosporine-A concentrations were similar in both groups. These results show that PHELA did not stimulate Th1 cytokines of a normal immune system but stimulated them when the immune system was suppressed by cyclosporineA. In conclusion, PHELA is an immune-stimulant to a compromised immune system.
\end{abstract}

Key words: PHELA, traditional medicine, cyclosporine-A, cytokines, immune stimulant

\section{Introduction}

The human immunodeficiency virus (HIV) is a retrovirus that leads to acquired immunodeficiency syndrome (AIDS). HIV infects the immune sytem, making the host unable to control the virus and at the same time more susceptible to infections by other pathogens. It targets the major immune cells, CD-4 T cells, macrophages and microglial cells. Symptomatic HIV infection is characterized by emergence of opportunistic infections and cancers in different body systems that the immune system would normally prevent.

Since the first cases of acquired immunodeficiency syndrome (AIDS) were reported in 1981, the infection has grown to pandemic proportions, resulting in an estimated 65 million infections and 25 million deaths globally. In 2008, about 33.4 million people were living with HIV, of whom 2.7 million more people were newly infected with HIV and 2.0 million die of AIDS (UNAIDS, 2009). Although HIV and AIDS are found in all parts of the world, some areas are more afflicted than others. The worst affected region is the sub-Saharan Africa, where in some countries, more than one in five adults is infected with HIV. South Africa experienced one of the most severe AIDS epidemics in history whereby by the end of 2008 , there were 5.7 million people living with HIV in South Africa (UNAIDS, 2008).

On the other hand, the use of anti-retroviral (ARV) drugs has lead to decreased HIV related morbility and mortality (WHO et al, 2009). Unfortunately, the ARV drugs do not cure the disease and are not accessible to all patients that need them (WHO et al, 2010). Also ARV drugs can cause adverse effects that include metabolic disorders and these worsen with chronic therapy (Carr and Cooper, 2000). This implies that ARV drugs are not the sole solution to eradication of the virus. However, it is well established that improvement during ARV drug therapy is paralleled with improved immune response, which highlights the need for boosting the immune system in controlling progression of HIV disease (Vicenzi and Biswas, 1997). There is a need for immune boosters that can enhance and stimulate the immune system and, if possible, to be used in combination with ARV drugs.

PHELA is a name given to the herbal mixture of four African traditional medicinal plants [Clerodendrum glabrum, Polianthes tuberosa, Rotheca myricoides and Senna occidentails] which has been traditionally used as remedies for wasting conditions, energy booster and some traditional health practitioner claim that these plants can help HIVIAIDS patients (Tshikalange et al, 2008). A subchronic toxicology study of PHELA in vervet monkeys showed no toxic effects on the test animals. In a phase I clinical trial in healthy human participants, no toxicity was observed [Medical Research Council, Indigenous Knowledge Systems Lead Programme report, 2009]. Clinical Observation study conducted using PHELA as an immune booster in 500 HIV/AIDS patients revealed an increase in the patient's appetite, $23 \%$ weight gain, $80 \%$ decrease in viral load and $200 \%$ increase in CD4 cell counts. Moreover, the overall quality of life of patients was increased from $30 \%$ to $100 \%$ (Matsabisa et al, 2006. An observational study of HIV positive and AIDS patients taking PHELA, a traditional Medicine, at Philisa Health Care Centre in Mabopane, North West province, South Africa from 2003 to 2005. Internal Report, MRC, South Africa). The latter has lead MRC-IKS into developing PHELA as an immune booster in HIV patients.

Unfortunately, the mechanism of action of PHELA on the immune system is not known. However, it is well known that the immune cells are regulated by cytokines and that the cytokine profile determines the type of immune response to any antigen (Romagnani, 1991; Hayney and Muller, 2003). Activation of type 1 helper T cell (Th1) leads to formation and activation of cytotoxic T-cells thereby conferring cell mediated immunity (CMI), while activation of type 2 Th cells (Th2) leads to formation and activation of B-cells for antibody response, which confers humoral immunity. The communication between the Th cells and the effector cytotoxic $T$ cells or B cells is through cytokines. The Th1 cells produce interferon-gamma (IFN- $\gamma$ ) and interleukin-2 (IL-2) and tumor necrosis factor-a (TNF-a), while Th2 cells produce interleukin-4 (IL-4) and interleukin-10 (IL-10). Therefore, it was envisaged that by observing changes in cytokine profiles, important information on the status of the immune system can be revealed and used to determine the mechanism of action of PHELA. 
Specifically, the aim of this study was to determine the effect of PHELA on the immune system by observing for subclinical changes in Th 1 cytokines (IL-2, IFN-y, TNF-a) that would enhance cell mediated immunity and Th 2 cytokines (IL-4 and IL-10) that would enhance the humoral response, with a hope that understanding the mechanism of action will help in designing immune booster therapy.

\section{METHODS}

PHELA was manufactured and supplied by the Indigenous Knowledge (IKS) Unit of the South African Medical Research Council. In our laboratory, PHELA powder was reconstituted for oral use by dissolving appropriate amounts in normal saline and filtration through a millpore membrane with pore size of $30 \mu \mathrm{m}$. Sterile normal saline (Euro-Med Laboratories Inc., Cavite, Philippines) and Influenza vaccine, Influvac subunit $2009^{\circledR}$ (Solvay Pharm. Pty Ltd, Johannesburg, South Africa) were purchased from a local pharmacy. The Influvac subunit 2009 contained $30 \mathrm{ug} / \mathrm{ml}$ of surface antigens of each the strains; A/Brisbane/59/2007(H1N1), A/Brisbane/10/2007 (H3N2) and B/Florida/4/2006. Cyclosporine was purchased from Sigma Aldritch Chemical Co. (St Loius, MI, USA). Enzyme-linked immunosorbent assay (ELISA) kits, Endogen ${ }^{\circledR}$, for rat TNF-a, IFN-y and IL-10 were purchased from Pierce Biotechnology, Inc. (Rockford, IL, U.S.A), while the ELISA kits for IL-2 and IFN- $\gamma$ were from Bender MedSystems (Vienna, Austria), and the rat IL-4 ELISA Set BD OptEIA ${ }^{\mathrm{TM}}$ was from BD Biosciences Pharmingen (San Diego, CA, USA).

\section{Animal care}

Ethical approval was obtained from the Animal Ethics Committee of the University of the Free State. Sprague-Dawley (SD) rats weighing $260-400 \mathrm{~g}$ were used. Animals were kept and treated at the Animal House of the University of the Free State where they were cared for by qualified staff according to International animal care guidelines. They were fed on Standard rat chow and water ad libitum, and the cages were cleaned twice a week. During treatment, animals were inspected for skin lesions and other visible adverse events every day.

\section{Experimental design}

The animals were divided into six groups whereby four groups had 8 rats each while the fifth group had 12 rats and the sixth group 4 rats. The four groups were treated daily with either normal-saline orally (control), cyclosporine $2 \mathrm{mg} / \mathrm{kg}$ in olive oil, subcutaneously (Cys: negative control), PHELA $15.4 \mathrm{mg} / \mathrm{kg}$ orally (test-group-1), and PHELA+cyclosporine (PHELA+Cys: test-group-2). Thereafter, 4 animals from each group were sacrificed after 7 and 14 days of treatment. The fifth group was inoculated once intramuscularly (laterally on the thigh) with influenza vaccine $0.2 \mathrm{ml}$ (positive control) after which 4 animals were sacrificed after 7,14 and 21 days. The sixth was not treated with anything (untreated), hence, was used to determine the status of immune system at base line (i.e., in unmanipulated animals).

\section{Surgical procedure and blood collection and analysis}

Under ether anaesthesia, blood $(8-10 \mathrm{ml})$ was drawn via cardiac puncture and immediately aliquoted into the appropriate testtubes. The rat was sacrificed by exsanguination whilst still under anaesthesia. Blood was collected for liver function tests and full blood count, PHELA concentration and cytokine analysis. Liver and renal functions tests and the full blood count were done by Pathcare Vetinary Laboratory (Bloemfontein, South Africa), while PHELA concentrations were measured by HPLC using a method developed in our laboratory and cyclosporine was analyzed by fluorescent Polarization Immuno-Assay (FPIA) using a Kit (cyclosporine assay for whole blood) according manufacturer's instruction (.Abbots Laboratories., Abbot Park, IL, USA). Serum cytokines, rat IL-2, IFN- $\gamma$, TNF- $a$, IL-4 and IL-10 were measured by ELISA on a UV-spectrophotometry with a microplate reader (HP, USA) and according to the manufacturer's instruction.

\section{Data analysis}

The response of cytokines to the treatment with different agents was evaluated by analysing the reponse pattern in the Th1 cytokines (IL-2, IFN- $y$ and TNF- $\alpha$ ) and Th2 cytokines (IL-4 and IL-10) versus the respective controls. Data was analyzed by non-parametric methods using the GraphPad Instat statistical program. Accordingly, summary data were reported as median and range, and the MannWhitney Test was used for data comparison with the level of significance set at $p<0.05$.

\section{Results \\ Physiological parameters}

Table 1 shows the changes in animals' weights, the liver and renal function tests over the treatment period. The change in weight was $0-1.8 \%$ in the first week, $1-5.5 \%$ in the second week, and $8.5 \%$ in the third week. This was within the expected range for age and all the changes in the different groups were similar to those of the control group. Also these changes in weight at 7 and 14 days did not warrant a change in drug dosage, while dosing was not applicable at 21 days after influenza vaccination because the vaccine was given once. Also, the liver function indicated by the ALT and ALK, and the renal function indicated by creatinine and urea, were normal. Table 2 and 3 illustrate the full blood count data. In Table 2, there were no changes in the WBC on the three occasions. However, Table 3 shows that there was significant reduction in the platelet count in the cyclosporine group on day 7 and 14, and this was antagonized by PHELA in the PHELA + cyclosporine group. 


\section{Cytokines profiles}

The effects of the different agents on the Th1 and Th2 cytokines tended to be more pronounced at 7 days of therapy. Thereafter, the cytokine levels in most cases either returned to baseline or were similar to those in the control group, most probably owing to endognous immune adjustments.

\section{Influenza vaccine}

Figure 1 shows that the effect of Influenza vaccine on Th1 cytokines (IL-2, IFN-y and TNF-a) and Th2 cytokines (IL-4 and IL-10) was not different from the control. However, the response to influenza vaccine treatment exhibited a trend whereby there was a raise in the levels of Th1 cytokines (IL-2, IFN-y and TNF-a) at 7 days followed by a progessive drop and return to base line, while the Th2 cytokines (IL-4 and IL-10) exhbited a downward trend without return to base line.

\section{Cyclosporine}

Figure 2 shows that treatment with cyclosporine lead to a reduction in the levels of Th1 cytokines (IL-2, IFN-y and TNF-a), and this was statistically significant for IL-2 at 7 days of treatment $(P=0.0357)$. Regarding Th2 cytokines, cyclosporine lead to a sharp raise in IL-10 at 7 days after which it returnred to baseline at 14 days of treatment. The corresponding concentrations of cyclosporine were 38 (3842) $\mathrm{ng} / \mathrm{ml}$ after 7 days and $88(38-116) \mathrm{ng} / \mathrm{ml}$ after 14 days of treatment.

\section{PHELA}

Figure 3 shows that the effect of treatment with PHELA on Th1 cytokines (IL-2, IFN-y and TNF-a) and Th2 cytokines (IL-4 and IL-10) was not different from the control. However, the response to PHELA exhibited a trend whereby there was a raise in the Th2 cytokines levels (IL-4 and IL-10) at 7 days followed by a progressive drop and return to base line. While the TH1 cytokines exhibited an upward trend without return to base line.

\section{PHELA + Cyclosporine}

In Figure 4, co-administration PHELA and cyclosporine lead to a reversal of the effects of cyclosporine, i.e., increased levels of Th1 cytokines (IL-2, IFN-y and TNF-a) versus reduced levels of Th2 cytokines (IL-4 and IL-10) at 7 days. Owing to wide variations, only the raise in IL-2 was statistically significant $(p=0.0357)$. The corresponding concentrations of cyclosporine were $66(52-160) \mathrm{ng} / \mathrm{ml}$ after 7 days and $68(48-76) \mathrm{ng} / \mathrm{ml}$ after 14 days of treatment. There was a significant difference between the concentrations cyclosporine only group versus those with $P H E L A+$ cyclosporine $(P=0.0167)$ but this was observed by 14 days of treatment $(P=0.2667)$.

\section{Discussion \\ Mechanism of action}

As indicated earlier, the cytokine profile determines the type of immune response to any antigen. Inncreased Th1 cytokines lead to $\mathrm{CMI}$, while increased Th2 cytokines leads to humoral immunity. In the case of viral infection, the CMI is effective in mediating removal of virus-infected cells, while the Th2 cytokines mediate production of antibodies to defend against viral invasion. However, the two cytokines must co-exist because they regulate each other regarding their actions whereby Th1 cytokines are pro-inflammatory while the Th2 are antiinflammatory, and in their production where some Th1 cytokines inhibit/stimulate release of specific Th2 cytokines and the vice versa.

Nevertheless, it is suffice to say that traditional medicines that increase Th1 cytokines would be the ideal candidates for development as immune boosters against established viral infections, while those that stimulate Th2 cytokines would be ideal for preventing viral infections. But, in this study, it has been demonstrated that PHELA acts on the immune system whereby it increased, al beit not statstically significant, the Th2 cytokines of a normal immune system at 7 days of treatment and increased or boosted the Th1 cytokines against cyclosporine induced immune suppression. Boosting in this case refers to the fact that the response to phale+cyclosporine treatment, particularly by IL-2, was higher than in the control and PHELA-only groups. This implies that PHELA has a dual action on cytokines in that it stimulates the relevant cytokines depending on the situation. The mild-moderate stimulation of Th2 cytokines of a normal immune system was probably to inhibit Th1 cytokine production and limit inflammation which was successfully achieved, while stimulation of Th1 cytokines when they were suppressed by cyclosporine was most appropriate action for the situation. Furthermore, this also implies that PHELA's actions on Th1 cytokines are more pronounced on a suppressed than on a normal immune system, which rhymes with the clinical observations studies where PHELA lead to improvement of immune markers in patients with a compromised immune system (Matsabisa G.M. and P Yako, 2006. An observational study of HIV positive and AIDS patients taking PHELA, a traditional Medicine, at Philisa Health Care Centre in Mabopane, North West province, South Africa from 2003 to 2005. Internal Report, MRC, South Africa). 
Table 1: Summary of the weights, and liver and renal function tests data (median \{range\}) for rats $(n=7)$ after 7, 14 and 21 days of treatment.

\begin{tabular}{|c|c|c|c|c|c|c|c|}
\hline \multirow[t]{2}{*}{ GROUP } & \multicolumn{2}{|c|}{ Weight } & \multirow[b]{2}{*}{$\begin{array}{l}\Delta \text { wt } \\
(\mathrm{g})\end{array}$} & \multicolumn{2}{|c|}{ Liver function tests } & \multicolumn{2}{|c|}{ Renal function tests } \\
\hline & $\begin{array}{l}\text { Before Rx } \\
\text { (g) }\end{array}$ & $\begin{array}{l}\text { After Rx } \\
\text { (g) }\end{array}$ & & $\begin{array}{l}\text { ALT } \\
\text { (U/L) }\end{array}$ & $\begin{array}{l}\text { ALK } \\
\text { (U/L) }\end{array}$ & $\begin{array}{l}\text { Creatinine } \\
\text { (mg/dl) }\end{array}$ & $\begin{array}{l}\text { Urea } \\
\text { (mg/dl) }\end{array}$ \\
\hline \multicolumn{8}{|l|}{7 DAYS OF TREATMENT } \\
\hline Saline (control) & $396 \pm 15$ & $403 \pm 17$ & 7.0 & $54(51-60)$ & $272(211-295)$ & $29(22-59)$ & $7.1(6.0-7.7)$ \\
\hline Influenza vac. (+ve control) & $405 \pm 11$ & $409 \pm 12$ & 4.0 & $57(47-65)$ & $254(199-284)$ & $41(27-47)$ & $7.1(6.7-7.7)$ \\
\hline Cyclosporine (-ve control) & $396 \pm 15$ & $400 \pm 13$ & 4.0 & $47(47-50)$ & $327(233-359)$ & $31(25-31)$ & $9.1(8.2-9.2)$ \\
\hline Phela & $377 \pm 23$ & $379 \pm 24$ & 3.0 & $53(50-91)$ & $293(192-361)$ & $32(24-56)$ & $7.5(6.8-8.7)$ \\
\hline Phela + cyclosporine & $405 \pm 17$ & $402 \pm 20$ & -3.0 & $51(34-61)$ & $213(181-242)$ & $37(27-42)$ & $6.6(6.2-7.6)$ \\
\hline \multicolumn{8}{|l|}{14 DAYS OF TREATMENT } \\
\hline Saline (control) & $405 \pm 18$ & $422 \pm 23$ & 17.0 & $59(57-62)$ & $300(260-327)$ & $26(20-34)$ & $7.5(6.4-8.0)$ \\
\hline Influenza vac. (+ve control) & $396 \pm 13$ & $411 \pm 19$ & 15.0 & $56(48-84)$ & $263(239-278)$ & $32(19-44)$ & $7.1(6.4-7.8)$ \\
\hline Cyclosporine (-ve control) & $392 \pm 33$ & $396 \pm 1$ & 4.0 & $36(36-51)$ & $240(171-292)$ & $20(15-37)$ & $7.2(6.9-8.1)$ \\
\hline Phela & $402 \pm 9$ & $424 \pm 12$ & 22.0 & $55(52-69)$ & $255(184-297)$ & $30(25-40)$ & $6.4(6.0-7.0)$ \\
\hline Phela + cyclosporine & $386 \pm 20$ & $403 \pm 16$ & 17.0 & $51(48-64)$ & $240(178-290)$ & $33(27-46)$ & $7.2(5.7-7.8)$ \\
\hline \multicolumn{8}{|l|}{21 DAYS OF TREATMENT } \\
\hline Influenza vaccine & $388 \pm 19$ & $421 \pm 21$ & 33.0 & $56(53-68)$ & $241(195-261)$ & $36(30-44)$ & $7.0(6.2-8.3)$ \\
\hline
\end{tabular}

Key: ALT: Alanine transaminase (17.5 - 30.2 U/L), ALK: Alkaline phosphates (56.8 - $128 \mathrm{U} / \mathrm{L})$; Creatinine $(0.2-0.8 \mathrm{mg} / \mathrm{dl})$, Urea $(15-21 \mathrm{mg} / \mathrm{dl})$ 
Table 2: Summary of White blood cells data \{median (range)\} after 7,14 and 21 days treatment.

\begin{tabular}{|c|c|c|c|c|c|c|}
\hline GROUP & $\begin{array}{l}\text { WCC } \\
\left(\times 10^{3} / \mathrm{mm}^{3}\right)\end{array}$ & $\begin{array}{l}\text { Neutrophils } \\
\left(\times 10^{3} / \mathrm{mm}^{3}\right)\end{array}$ & $\begin{array}{l}\text { Lymphocytes } \\
\left(\times 10^{3} / \mathrm{mm}^{3}\right)\end{array}$ & $\begin{array}{l}\text { Monocytes } \\
\left(\times 10^{3} / \mathrm{mm}^{3}\right)\end{array}$ & $\begin{array}{l}\text { Eosinophils } \\
\left(\times 10^{3} / \mathrm{mm}^{3}\right)\end{array}$ & $\begin{array}{l}\text { Basophils } \\
\left(\times 10^{3} / \mathrm{mm}^{3}\right)\end{array}$ \\
\hline \multicolumn{7}{|l|}{ 7DAYS TREATMENT } \\
\hline Saline & $6.5(3.5-8.2)$ & $0.53(0.63-1.37)$ & $5.06(2.82-7.33)$ & $0.06(0.04-0.20)$ & $0.11(0.02-0.14)$ & $0.06(0.04-0.10)$ \\
\hline Influenza vaccine & $4.2(3.6-6.0)$ & $0.72(0.58-0.91)$ & $3.49(2.63-4.95)$ & $0.02(0.02-0.14)$ & $0.09(0.07-0.11)$ & $0.04(0.02-0.05)$ \\
\hline Cyclosporine & $6.5(4.6-7.0)$ & $0.64(0.43-0.98)$ & $5.14(3.66-6.30)$ & $0.16(0.16-0.26)$ & $0.06(0.03-0.13$ & $0.03(0.03-0.09)$ \\
\hline Phela & $4.7(4.1-5.9)$ & $0.58(0.44-0.77)$ & $3.59(3.51-4.78)$ & $0.08(0.04-0.18)$ & $0.10(0.08-0.18)$ & $0.05(0.05-0.07)$ \\
\hline Phela + Cyclosporine & $3.8(4.3-6.7)$ & $0.53(0.64-0.77)$ & $3.05(3.33-5.58)$ & $0.08(0.09-0.15)$ & $0.05(0.09-0.16)$ & $0.07(0.05-0.08)$ \\
\hline \multicolumn{7}{|l|}{14 DAYS TREATMENT } \\
\hline Saline & $4.4(3.2-6.5)$ & $0.61(0.54-0.88)$ & $3.38(2.49-5.39)$ & $0.05(0.02-0.16)$ & $0.04(0.03-0.11)$ & $0.06(0.04-0.12)$ \\
\hline Influenza vaccine & $2.0(4.3-5.0)$ & $0.79(0.11-0.91)$ & $3.20(1.42-4.12)$ & $0.04(0.04-0.08)$ & $0.09(0.04-0.11)$ & $0.04(0.03-0.05)$ \\
\hline Cyclosporine & $7.5(3.3-9.1)$ & $1.10(0.46-1.35)$ & $5.70(2.61-7.63)$ & $0.19(0.17-0.45)$ & $0.03(0.03-0.07)$ & $0.18(0.03-0.04)$ \\
\hline Phela & $3.6(2.8-4.9)$ & $0.54(0.30-0.71)$ & $3.11(2.16-3.70)$ & $0.06(0.02-0.16)$ & $0.08(0.02-0.11)$ & $0.05(0.04-0.17)$ \\
\hline Phela + cyclosporine & $5.3(4.7-7.3)$ & $0.92(0.61-1.48)$ & $4.16(3.59-5.87)$ & $0.17(0.05-0.19)$ & $0.09(0.06-0.11)$ & $0.11(0.06-0.16)$ \\
\hline \multicolumn{7}{|l|}{21 DAYS TREATMENT } \\
\hline Influenza vaccine & $5.3(3.6-5.9)$ & $0.65(0.53-0.81)$ & $3.87(0.58-4.84)$ & $0.09(0.03-0.30)$ & $0.09(0.06-0.16)$ & $0.09(0.06-0.11)$ \\
\hline
\end{tabular}

Key: WCC: white cell count, Neutrophils $(1.77-3.38)$, Lymphocytes $(4.78-9.12)$, Eosinophils $(0.03-0.08)$, Monocytes $(0.01-0.04)$, Basophils $(0.00-0.03)$ 
Table 3: Summary of Red blood cells data \{median (range)\} for rats $(n=7)$ after 7,14 and 21 days treatment.

\begin{tabular}{|c|c|c|c|c|c|c|c|}
\hline GROUP & $\begin{array}{l}\text { RCC } \\
\left(\times 10^{3} / \mathrm{mm}^{3}\right)\end{array}$ & $\begin{array}{l}\text { Haemoglobin } \\
\text { (g/dl) }\end{array}$ & $\begin{array}{l}\text { Haematocrit } \\
\text { (I/I) }\end{array}$ & $\begin{array}{l}\text { MCV } \\
\text { (fl) }\end{array}$ & $\begin{array}{l}\mathrm{MCH} \\
(\mathrm{pg})\end{array}$ & $\begin{array}{l}\text { MCHC } \\
(\mathrm{g} / \mathrm{dl})\end{array}$ & $\begin{array}{l}\text { Platelet count } \\
\left(\times 10^{3} / \mathrm{ml}\right)\end{array}$ \\
\hline \multicolumn{8}{|l|}{7 DAYS TREATMENT } \\
\hline Saline & $9.1(8.4-9.2)$ & $16.2(15.2-16.4)$ & $0.70(0.68-0.73)$ & $78(77-81)$ & 18 & 23 & $1051(322-1154)$ \\
\hline Influenza vaccine & $8.7(2.2-9.1)$ & $16.4(16.2-17.3)$ & $0.70(0.18-0.75)$ & $80(78-82)$ & $19(18-19)$ & 23 & $1105(213-1177)$ \\
\hline Cyclosporine & $7.7(6.4-8.0)$ & $15.2(11.8-15.4)$ & $0.69(0.57-0.69)$ & $88(87-89)$ & $19(18-20)$ & $22(21-22)$ & $584(124-1067)$ \\
\hline Phela & $8.7(8.4-8.9)$ & $15.8(15.8-16.0)$ & 0.69 & 79 (78 - 82) & $18(18-19)$ & 23 & $1032(746-1164)$ \\
\hline Phela + Cyclosporine & $8.3(8.1-9.1)$ & $15.6(15.0-16.8)$ & $0.68(0.66-0.73)$ & $81(80-81)$ & $19(18-19)$ & 23 & $1101(1020-1134)$ \\
\hline \multicolumn{8}{|l|}{14 DAYS TREATMENT } \\
\hline Saline & $8.7(8.0-8.9)$ & $16.0(15.0-16.2)$ & $0.69(0.66-0.71)$ & $80(79-82)$ & $19(18-19)$ & $23(23-24)$ & $1023(212-1174)$ \\
\hline Influenza vaccine & $8.7(6.9-9.9)$ & $16.4(12.8-16.9)$ & $0.71(0.56-0.74)$ & $82(78-82)$ & $19(18-19)$ & $23(23-24)$ & $1057(126-1257)$ \\
\hline Cyclosporine & $7.6(7.2-8.0)$ & $15.0(13.6-15.3)$ & $0.67(0.62-0.69)$ & $88(86-88)$ & $19(19-20)$ & $22(22-23)$ & $91(74-1186)$ \\
\hline Phela & $8.8(8.3-9.3)$ & $16.0(15.7-16.9)$ & $0.69(0.68-0.72)$ & $80(77-82)$ & $19(18-19)$ & $23(23-24)$ & $1005(427-1264)$ \\
\hline Phela + Cyclosporine & $8.8(6.4-9.4)$ & $16.3(15.7-18.0)$ & $0.70(0.48-0.75)$ & $78(75-80)$ & $18(17-25)$ & $23(23-34)$ & $1062(481-2392)$ \\
\hline \multicolumn{8}{|l|}{21 DAYS TREATMENT } \\
\hline Influenza vaccine & $8.9(8.3-9.3)$ & $16.0(15.5-16.6)$ & $0.71(0.67-0.73)$ & $79(78-81)$ & $18(18-19)$ & 23 & $1023(136-1130)$ \\
\hline
\end{tabular}

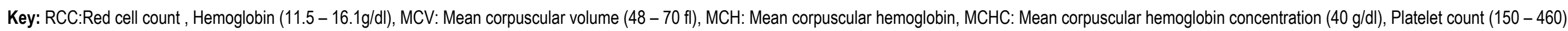


Interaction with cyclosporine

The interaction between PHELA and cyclosporine is unlikely to be a pharmacokinetic interaction as the concentrations of cylosporine were not different in the two groups, i.e., cyclosporine group vs. phale+cyclosporine group. The difference in concentrations of cylosporine after 7 days of treatment was most probably due to delayed absorption from the subcutaneous injection site in the cyclosporine only group. Also, preliminary studies in our laboratory in which the effect of PHELA on the activity of each the five major human drug metabolizing cytochrome P450 isoforms (CYP2D6, CYP3A4, CYP1A2, CYP2C19, and CYP2C9) were studied, showed that PHELA had no significant effect on the activity of any of these iso-enzymes, especially CYP3A. CYP3A is the enzyme responsible for cyclosporine metabolism. Furthermore, treatment of rats with PHELA at the same dose used here for 3 and 7 days had no effect on the activity of rat CYP3A and other enzymes, and this was confirmed by quantification of CYP3A by SDS-PAGE and Western Blot method. Therefore, the mechanism by which PHELA interacted with cyclosporine is not clear.

PHELA also antagonized the effect of cyclosporine on platelets. Cyclosporine is known to cause thrombotic thrombocytopenic purpura due to its activation of platelet aggregation (Lian, 1980; Grace et al, 1987; Phadke and Bagirath, 2004) and depletion of prostacyclin-stimulating factor (Neild et al, 1983; Leithner et al, 1982). Unfortunately, this study did not evaluate for these factors, hence, the mechanism by which PHELA prevented the cyclosporine induced thrombocytopenia is not known.

On the other hand, since PHELA alone had no effect on the Th1 cytokines, one might say that cyclosporine augmented the action of PHELA, but this remains to be confirmed. In the same perspective, the effects of PHELA could be considered as not different from a dietary supplement which can aid restoration of a pathological situation with no further effect on a normal immune system. Well then, the latter calls for a review of the dietary recommendations in immune compromised patients because some foods such as PHELA would be more relevant than others.

Lastly, the findings of this study are also important in the chemotherapy for transplant patients, as they high lighted a potential adverse interaction between PHELA and cyclosporine that can lead to graft rejection. Therefore, transplant patients using cyclosporine should not use PHELA products.

\section{Optimum Time to evaluate cytokine response}

It was observed that cytokine profiles varied with the time lapse since administration of the drugs. For instance, except in a few cases, the response at 7 days was always reversed or weaker by $14^{\text {th }}$ day of treatment. This was most probably because the immune system countered the disruption of the respective immune mediators. It could also account for the failure by PHELA to stimulate a normal immune system but it was not clear whether the response to PHELA would be more remarkable beyond 14 days. Nevertheless, this study has demonstrated that the time period since administration of the test antigen is important for interpretation of cytokine response to antigens. It was therefore appropriate in this study to use the response at 7 days as more relevant than at 14 days even though both occasions were considered in the analysis.

\section{Positive and negative controls}

Since most studies on cytokine are characterized by wide variations in cytokine response that make, not only interpretation of data very difficult, but also cast doubt on the robustness of the experimental methods used, it was decided to include the positive and negative controls using drugs which immune response is well characterized, i.e., influenza vaccine and cyclosporine, respectively. The conviction was that if the experiment can reproduce the expected response by the two drugs, it would confirm the observations in all other groups as robust.

Regarding the response to influenza vaccine, wide variation in cytokine response to the different Influenza vaccines has been reported (Tsai et al., 2005; Krakauer and Russo, 2001; McElhaney et al, 1995; Mcelhaney et al, 2002; Mcelhaney et al, 1998; McElhaney et al, 1992; Tamizifar et al, 1997; Saurwein-Teiss et al, 1998). Nevertheless, most of these studies demonstrated a raise or no effect on Th1 cytokines (IL-2, IL-12, TNF-á, and IFN-Y) with minimal effect on Th2 cytokines (McElhaney et al, 1995; Mcelhaney et al, 2002; McElhaney et al, 1992; Tamizifar et al, 1997; Saurwein-Teiss et al, 1998), while a some have demonstrated a raise in TH2 cytokines as well (Virelizier et al, 1974; Mitchell and Callard, 1983). Also, the response by Th1 cytokines was stronger with whole virus vaccine than with subunit vaccines (McElhaney et al, 1995; Saurwein-Teiss et al, 1998). In the current study, Influvacc 2009 is a trivalent subunit vaccine which, as expected, induced a mild increase in the Th1 cytokines on day 14 and moderate increase in the Th2 cytokines at day 7. Even then, our follow up was for only 21 days, yet it was observed in humans that increase in cytokines after Influenza vaccination may reach maximum between 3 and 12 weeks (McElhaney et al, 1995). As such, it is likely that Th1 cytokines could have been higher after 21 days. Unfortunately, since the age corresponding to 12 weeks in rats is not known, monitoring rats for 12 weeks could not be done because the effects of aging may influence response to the influenza vaccine (Krakauer and Russo, 2001; McElhaney et al, 1995; Mcelhaney et al, 2002; Mcelhaney et al, 1998; McElhaney et al, 1992;). In conclusion, in this study, the response to influvaac 2009 was as expected; a mild effect on Th1 cytokines and moderate suppression of Th2 cytokines, and this imparted a CMl (Mcelhaney et al, 1998). 

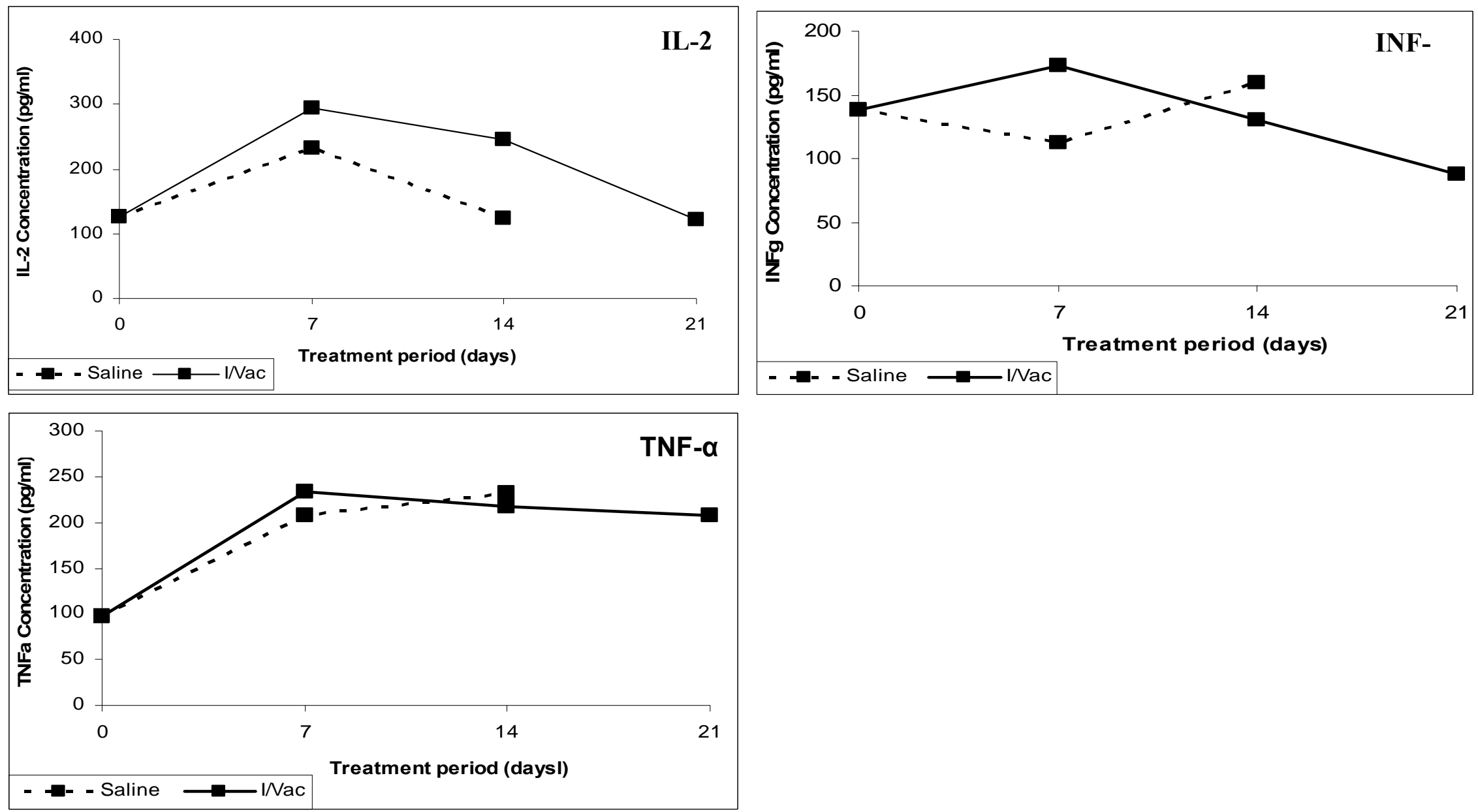

Figure 1a: The effect of Influenza vaccine on IL-2, INF- $y$, and TNF-a in healthy rats $(n=7)$ 

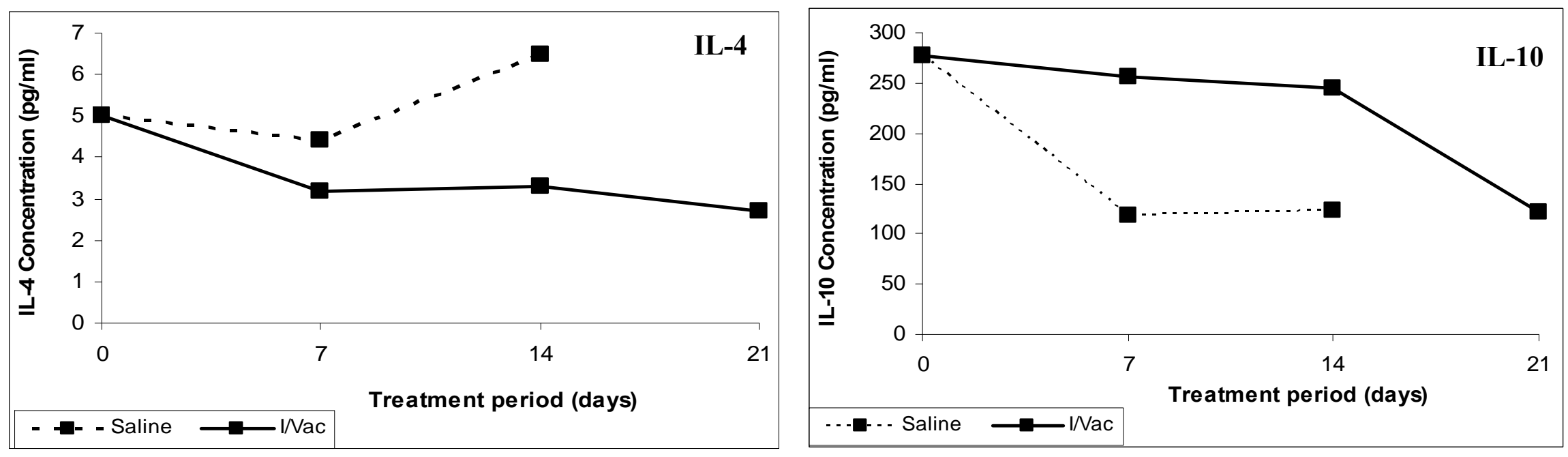

Figure 1b: The effect of Influenza vaccine on IL-4 and IL-10 in healthy rats $(n=7)$ 

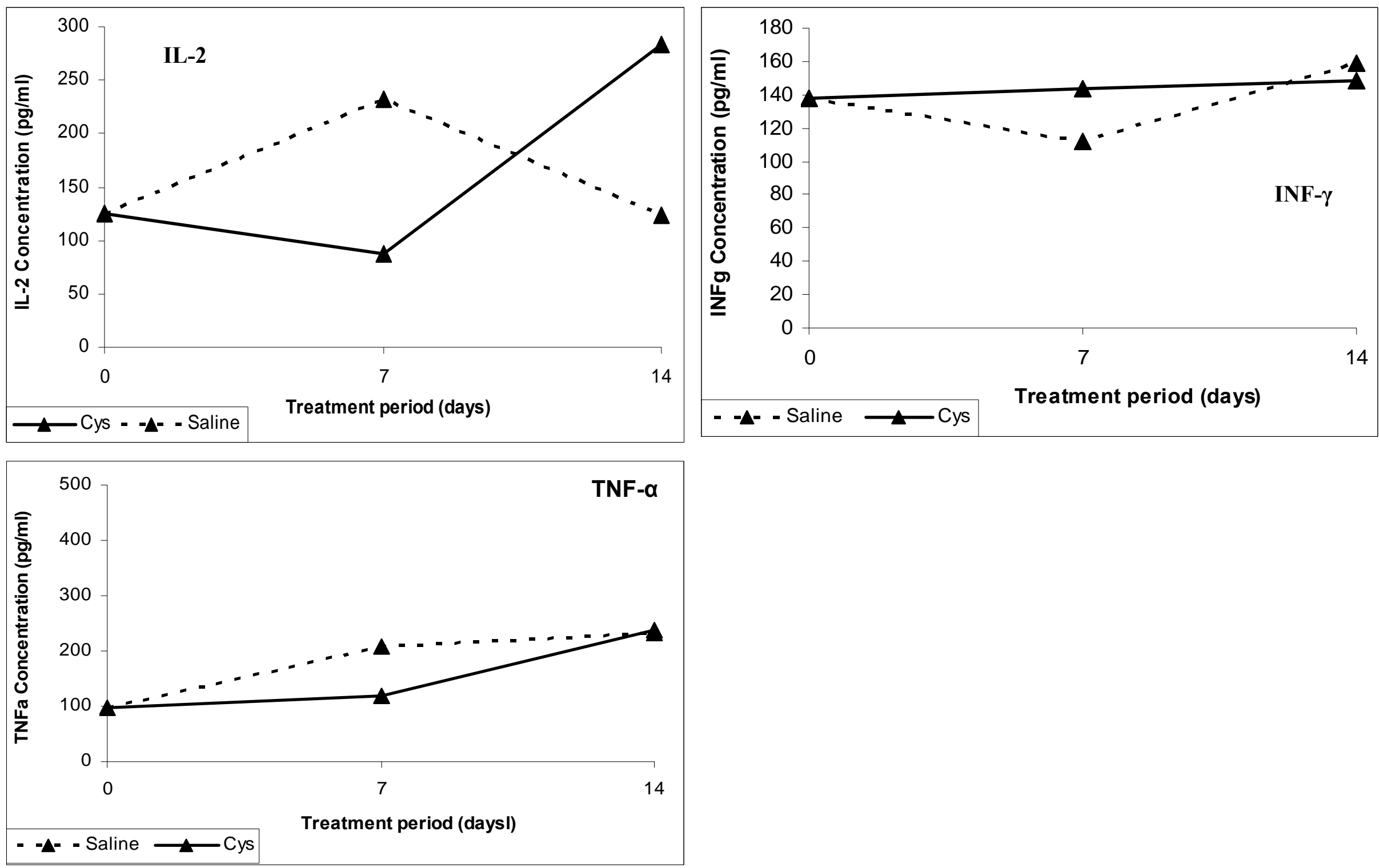

Figure 2a: The effect of Cyclosporine on IL-2, INF-y, and TNF-a in healthy rats $(n=7)$. 

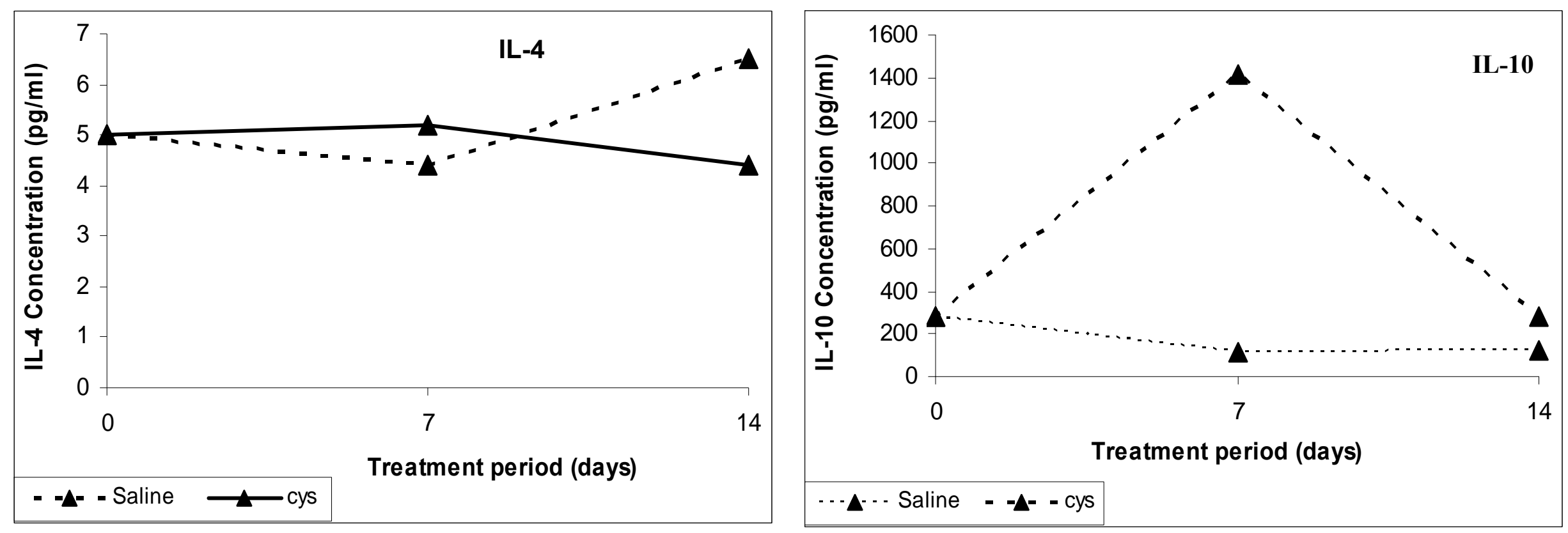

Figure 2b: The effect of Cyclosporine on IL-4 and IL-10 in healthy rats $(n=7))$. 

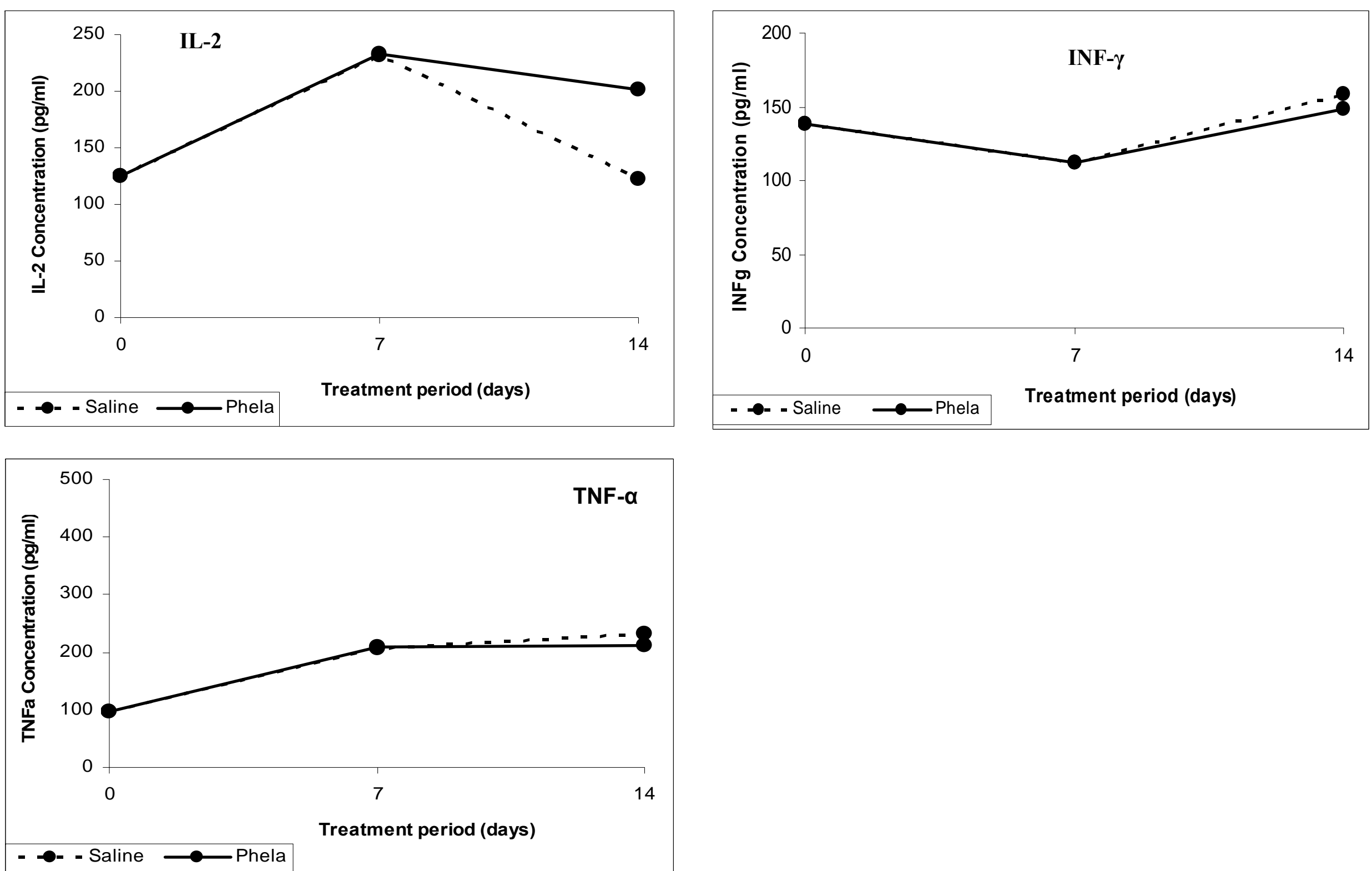

Figure 3a: The effect of PHELA on IL-2, INF-y and TNF-a in healthy rats $(n=7)$. 

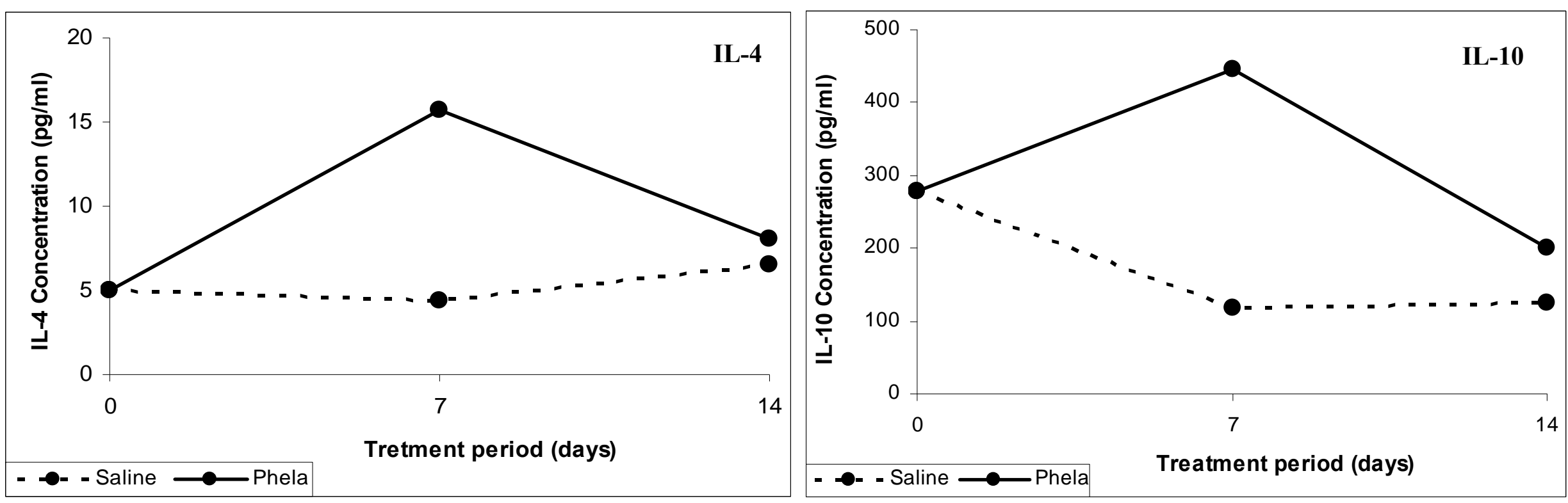

Figure 3b: The effect of PHELA on IL-4 and IL-10 in healthy rats $(n=7)$ ). 

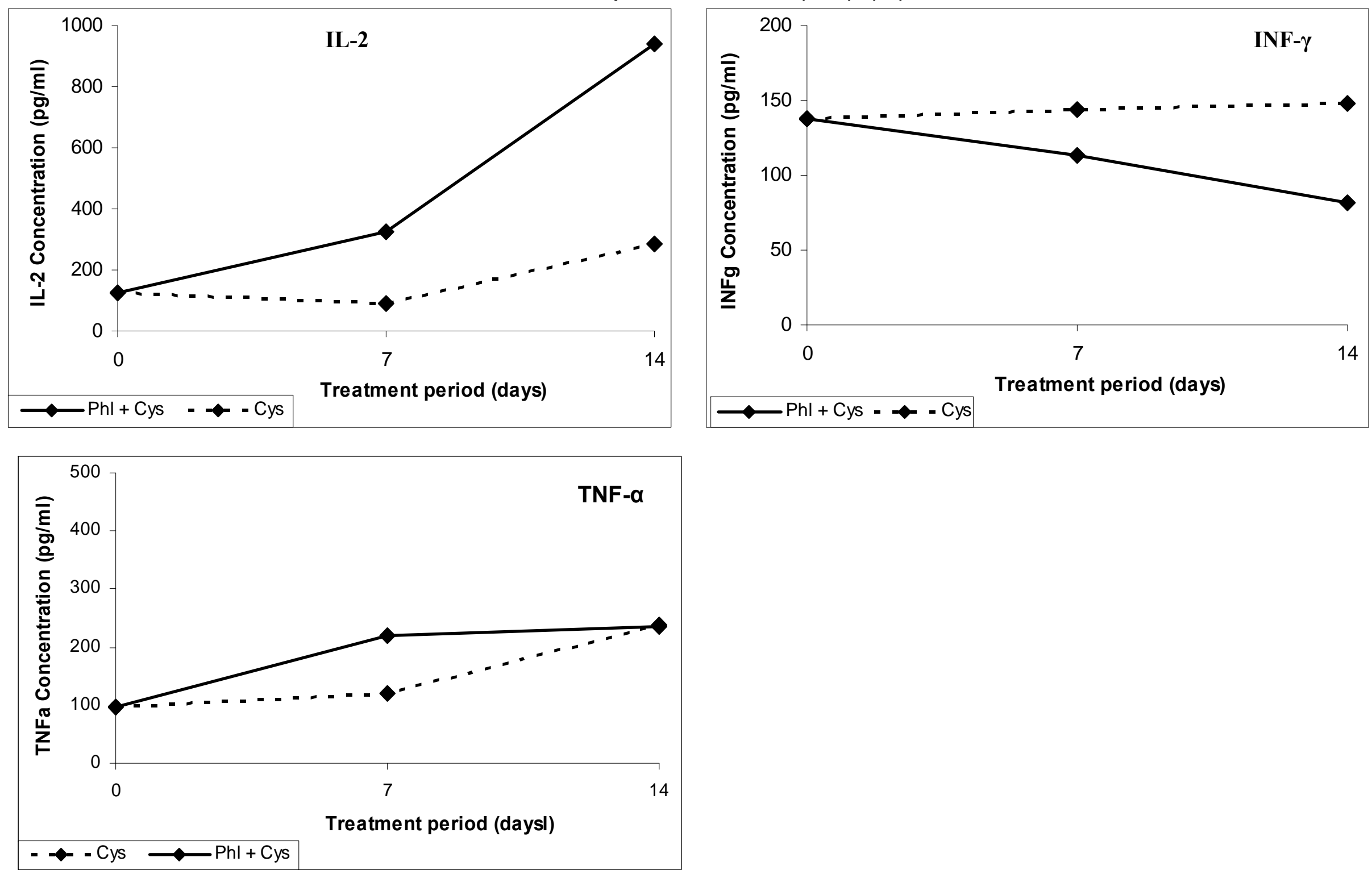

Figure 4a: The effect of PHELA on IL-2, INF-y and TNF-a during co-administration with cyclosporine in healthy rats $(n=7)$. 

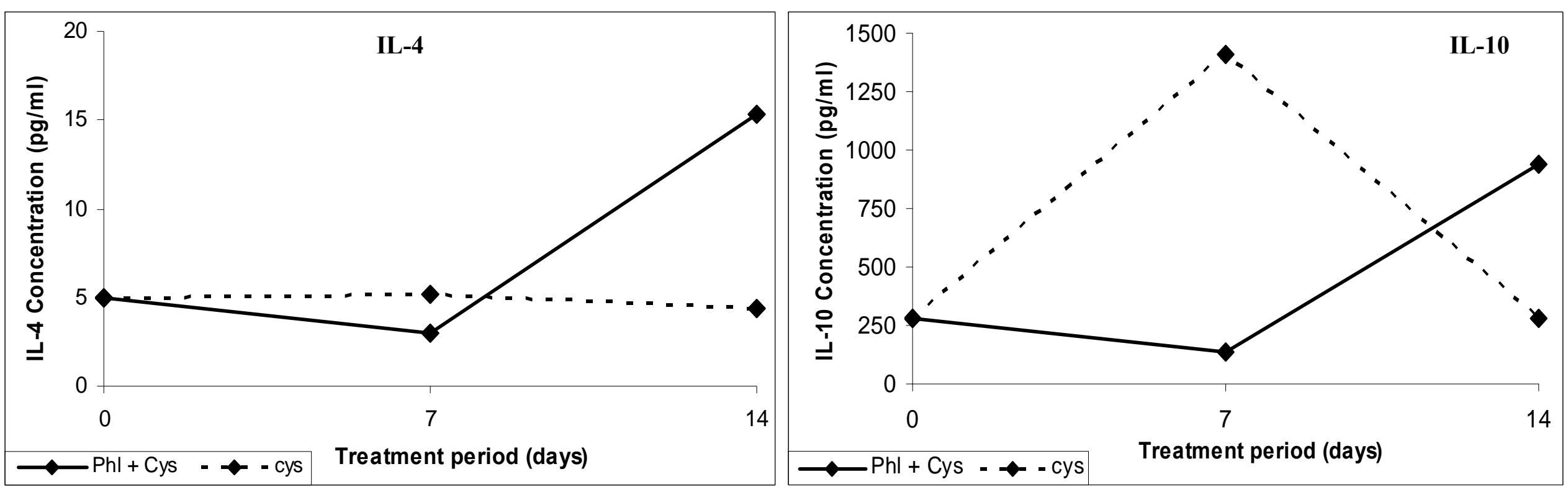

Figure 4b: The effect of PHELA on IL-4 and IL-10 during co-administration with cyclosporine in healthy rats $(n=7)$. 
Regarding cyclosporine, the current study, like in other studies elsewhere, demonstrated that cyclosporine inhibits production of Th1 cytokines (II-2, TNF-á, IFN- $\gamma$ ) while increasing production of IL-10 with minimal or no effect on IL-4 (Corsini et al, 2006; Alberu et al, 2001; Cho et al, 2002; Kim et al, 2000; Andersson et al, 1992; Bonnotte et al, 1996; Kim et al, 2000). Therefore, in spite of the wide variations that might have led to lack of statistically significant differences, the observations on the effects of PHELA on the immune system are accurate. In fact, the effect of cyclosporine on cytokines, especially IL-10, was suggested to be at transcriptional level because cyclosporine increased the IL-10 mRNA (Cho et al, 2002). It is therefore most probable that PHELA interacts with cyclosporine at transcriptions level, but this too remains to be confirmed.

In conclusion, using a rat model, it has been demonstrated that PHELA is an immune stimulant that antagonizes the effects of cyclosporine with minimal effect on a normal immune system in first 14 days of treatment. This implies that PHELA is an ideal candidate for further evaluation and development into an immune booster medication.

\section{References}

1. Alberu J., Richaud-Patin Y., Mancilla E., Di'liz H., Correa-Rotter R., Chew-Wong A., Uribe N., de Leo C. and Llorente L. (2001). Effect of Cyclosporine Withdrawal on IL-10 Production in Kidney Transplant Recipients. Transplant Proc, 33: 2024-2027

2. Andersson J., Nagy S., Groth C.G., Andersson U., (1992). Effects of FK 506 and cyclosporine A on cytokine production studied in vitro at single cell level. Immunology, 75: 136-142.

3. Bonnotte B., Pardoux C., Bourhis J.H., Caignard A., Burdiles A.M., Chehimi J., Mami-Chouaib F., Chouaib S., (1996). Inhibition of human allogeneic mixed lymphocyte response by cyclosporine A: relationship with IL-12 pathway. Tissue Antigens, 48: 265-270.

4. Carr A. and Cooper D.A., (2000). Adverse effects of Antiretroviral therapy. The Lancet, 356: $1423-1430$.

5. Cho M.L., Kim W.U., Min S.Y., Min D.J., Min J.K., Lee S.H., Park S.H., Cho C.S., and Kim H.Y., (2002). Cyclosporine Differentially Regulates Interleukin-10, Interleukin-15, and Tumor Necrosis Factor-á Production by Rheumatoid Synoviocytes. Arthritis and Rheum., 46: 42-51.

6. Corsini E., Vismara L., Lucchi L., Viviani B., Govoni S., Galli C.L., Marinovich M., and Racchi M., (2006). High interleukin-10 production is associated with low antibody response to influenza vaccination in the elderly. J. Leukoc. Biol., 80: 376-382.

7. Grace A.A., Barradas M.A., Mikhailidi D.P., Jeremy J.Y., Moorhead J.F., Sweny P., and Dandona P, (1987). Cyclosporine A enhances platelet aggregation. Kidney Int, 32: 889-895

8. Hayney M.S. and Muller D. (2003). Effect of Influenza Immunization on CYP3A4 Activity In Vivo. J. Clin. Pharmacol., 43: 1377-1381

9. Kim W.U., Cho M.L., Kim S.I., Yoo W.H., Lee S.S., Joo Y.S., Min J.K., Hong Y.S., Lee S.H., Park S.H., Cho C.S., Kim H.Y., (2000). Divergent effect of cyclosporine on Th1/Th2 type cytokines in patients with severe, refractory rheumatoid arthritis. J. Rheumatol., 27: 324331.

10. Krakauer T. and Russo C., (2001). Serum Cytokine Levels and Antibody Response to Influenza Vaccine in the Elderly. Immunopharmacol. and Immunotoxicol., 23: 35-41

11. Leithner C., Sinzinger H., Pohanka E., Schwarz M., Kretschmer G., Syne G., (1982). Recurrence of haemolytic uraemic syndrome triggered by cyclosporine A after renal transplantation (letter). Lancet, I: 1470.

12. Lian E.C., (1980). The role of increased platelet aggregation in TTP. Semin. Thromb. Hemost., 6: 401-415.

13. Mcelhaney J.E., Gravenstein S., Hooton J.W., Arora A., (2002). The Effect of a Booster Vaccination on T-Cell Responses to Influenza Vaccination in Older Adults. Proceedings of the Intersc. Conf. Antimicr. Agents Chemother. Sept. 27-30; abstract no. G-145. 42:

14. McElhaney J.E., Meneilly G.S., Beattie B.L., Helgason C.D., Lee S.F., Devine R.D.O. and Bleackley R.C., (1992). The Effect of Influenza Vaccination on IL2 Production in Healthy Elderly: Implications for Current Vaccination Practices. J. Gerontol., 47: M3-M8

15. McElhaney J.E., Meneilly G.S., Pinkoski M.J., Lechelt K.E. and Bleackley R.C., (1995). Vaccine-related determinants of the interleukin-2 response to influenza vaccination in healthy young and elderly adults. Vaccine, 13: 6-10.

16. Mcelhaney J. E., Gravenstein S., Upshaw C. M., Hooton J. W., Krause P., and Drinka P., (1998). Immune response to influenza vaccination in institutionalized elderly: effect on different T-cell subsets. Vaccine, 16: 403-409.

17. Mitchell, D.M. and Callard, R.E., 1983. Fine specificity of the in vitro antibody response to influenza virus by human blood lymphocytes. J. Immunol., 131: 1229-1233.

18. Neild O.H., Rocchi G., Imberti L., Fumagalli F., Brown Z., Remuzzi G., Williams D.G., (1983). Effect of cyclosporin A on prostacyclin synthesis by vascular tissue. Thromb. Res., 32: 373-379

19. Phadke K. and Bagirath A., (2004). Mycophenolate mofetil as an alternative to cyclosporine in post renal transplant thrombocytopenia. Pediatr. Nephrol., 19: 822-823

20. Romagnani S., (1991). Human Th1 and Th2 subsets: doubt no more. Immunol. Today, 12: 256-257.

21. Saurwein-Teiss I. M., Zisterer K., Sc.hmitt T.L., Gluck R., Cryz S. and Grubeck-Loebenstein B., (1998). Whole virus influenza vaccine activates dendritic cells (DC) and stimulates cytokine production by peripheral blood mononuclear cells (PBMC) while subunit vaccines support T cell proliferation. Clin. Exp. Immunol., 114: 271-276

22. Tamizifar H., Jennings R., Ali S.A. and Potter C.W., (1997). Induction of IL-2 and IFN-7 in BALB/c mice immunised with subunit influenza A vaccine in combination with whole cell or acellular DTP vaccine. Med. Microbiol., 46: 61-66.

23. Tsai M.Y., Hanson N.Q., Straka R.J., Hoke T.R., Ordovas J.M., Peacock J.M., Arends V.L., Arnett D.K., (2005). Effect of influenza vaccine on markers of inflammation and lipid profile. J. Lab. Clin. Med., 145: 323-327. 
24. Tshikalange T.E., Meyer J.J.M., Lall N., Muñoz E., Sancho R., Van de Venter M. and Oosthuizen V., (2008). In vitro anti-HIV-1 properties of ethnobotanically selected South African plants used in the treatment of sexually transmitted diseases. J. Ethnopharmacol., 119: 478-481.

25. UNAIDS, (2008). Report on the global AIDS epidemic. Geneva, UNAIDS, ISBN 978929173717 8, Geneva, Switzerland http://data.unaids.org/pub.GlobalReport2008/jc1511_gr08_executivesummary_en.pdf (Accessed 21 January 2012)

26. UNAIDS, (2009). AIDS Epidemic Update. Geneva, UNAIDS. ISBN 978929173832 8, Geneva, Switzerland. http://data.unaids.org/pub/report/2009/jc1700:epi;update_2009_en.pdf (Accessed 21 January 2012)

27. Vicenzi E, and Biswas P., (1997). Role of pro-inflammatory cytokines and $\beta$-chemokines in controlling HIV replication. J. Leukoc. Biol., 62: $34-40$.

28. Virelizier J.L., Postlethwaite R., Schild G.C. and Allison A.C., (1974). Antibody responses to antigenic determinants of influenza virus hemagglutinin. J. Expt Medicine, 140: 1559-1570

29. WHO, UNAIDS and UNCEF, (2009). Towards universal access: scaling up priority HIVIAIDS interventions in the health sector. 2009 Progress report. Geneva. ISBN $978 \quad 92 \quad 4 \quad 159875 \quad 0 \quad$ (NML Classification WC 503.6). http://data.unaids.org/pub/Report/2009/20090930_tuapr_2009.en.pdf (Accessed 21 January 20120

30. WHO, UNAIDS and UNCEF, (2010). Treatment and Care for people living with HIV, Chapter 4. In: Towards Universal Access, Scaling up priority HIVIAIDS interventions in the health sector, $2010 \quad$ ISBN $978 \quad 92 \quad 4 \quad 150039 \quad 5, \quad p \quad$ 23-44 http://www.who.int/publications/2010/9789241500395:eng.pdf (Accessed 21 January 2012) 